\title{
Rapid decline and shift in the future distribution predicted for the endangered Sokoke Scops Owl Otus ireneae due to climate change
}

\author{
ARA MONADJEM, MUNIR Z. VIRANI, COLIN JACKSON and \\ APRIL RESIDE
}

\begin{abstract}
Summary
Climate change is predicted to have serious impacts on the conservation status of numerous species of birds, particularly low-density, range-restricted species occupying narrow habitats. One such species is the globally "Endangered" Sokoke Scops Owl Otus ireneae that currently survives in just two or three small pockets of forest in coastal Kenya and north-eastern Tanzania. We assessed the potential impact of changes in future climate on this species using predictive niche modelling. Distributional data were obtained from various published and unpublished sources, and field surveys. Maximum Entropy (Maxent) was used to model the current distribution of Sokoke Scops Owl. A general circulation model was used to predict the distribution of this species in 2080. This scenario predicts a southward shift in the future distribution of this species in Kenya and a complete disappearance from the Usambara mountains in Tanzania, with a concomitant $64 \%$ reduction in areas of high environmental suitability. Considering the isolated nature of the forest fragments in which this owl survives and the sea of inhospitable human-modified habitat which surrounds these fragments, the future conservation prospects of this species are bleak. Close monitoring of the species is strongly recommended and potential conservation interventions are discussed.
\end{abstract}

\section{Introduction}

Human-induced climate change is currently viewed as one of the principal threats to biodiversity conservation (Stott et al. 2000, Thomas et al. 2004). Mean global temperature has increased by $0.6^{\circ} \mathrm{C}$ since 1950 and is forecast to rise by around $3^{\circ} \mathrm{C}$ at the end of the current century (IPCC 2001). This warming at the global scale is predicted to result in significant changes (both increase and decrease) in precipitation and temperature at the local scale affecting habitats (Hannah et al. 2002), with impacts on the distribution and abundance of species (Erasmus et al. 2002, Keith et al. 2008).

Ecological responses of organisms to climate change have now been documented throughout the world (see Parmesan 2006 and references therein), with at least one species having become extinct as a direct result of climate change (Pounds et al. 1999). Impacts on birds have also been predicted and documented. For example, mean range shifts of more than $500 \mathrm{~km}$ to the north-east have been predicted for European nesting birds, with concomitant decrease in distributional range (Huntley et al. 2006, 2007, 2008). However, only a few studies have investigated the effect of climate change on the conservation status of birds in Africa (Erasmus et al. 2002, Simmons et al. 2004, Coetzee et al. 2009, Holt et al. 2009). These studies typically predict a decrease in distributional range (Thomas et al. 2004) and/or a decline in population size (Wichmann et al. 2003) over the next century, with some possible extinctions (Erasmus et al. 2002). The severity of these impacts has been considered to be related to ecological and life-history traits of the species; long-lived, territorial species with low reproductive rates, restricted global distributions and 
reliance on vulnerable habitats are especially at risk (Simmons et al. 2004). Birds of prey characteristically exhibit such features and may be prime candidates for studies on climate change (Wichmann et al. 2003).

The Sokoke Scops Owl Otus ireneae is a small, range-restricted species endemic to coastal Kenya and north-eastern Tanzania (Evans 1997, Virani et al. 2010) that is currently listed as globally "Endangered" (IUCN 2012). The listing was justified by the very small, severely fragmented range with declining habitat quality and the removal of nesting trees (IUCN 2012). Its entire global distribution consists of three small, isolated populations: 1 ) the adjoining Manga and Kwamgumi forest reserves covering $97 \mathrm{~km}^{2}$ in the lowlands of the East Usambara mountains, Tanzania (Evans et al. 1994, Virani 1995, Evans 1997); 2) the Arabuko-Sokoke Forest Reserve (ASF) containing $220 \mathrm{~km}^{2}$ of suitable habitat, coastal Kenya (Ripley 1966, Virani et al. 2010); and 3) the Dakatcha woodlands $30 \mathrm{~km}$ north of ASF covering an unknown area, Kenya (Virani et al. 2010). In total, therefore, its global range is unlikely to exceed $500 \mathrm{~km}^{2}$, and may well be less than $400 \mathrm{~km}^{2}$.

Two additional factors exacerbate the situation further; the species's restricted habitat requirements and the loss and fragmentation of this habitat. Despite the availability of three different forest habitats at ASF, the Sokoke Scops Owl occurs only in Brachylaena/Cynometra-dominated forest (Virani et al. 2010), avoiding Brachystegia and mixed forests. Forest cover outside ASF has disappeared over the past half-century in this region (Kelsey and Langdon 1984), and illegal harvesting of timber is affecting the forest quality within ASF (Thompson et al. 2007). The habitat of the Sokoke Scops Owl has not been quantified in the East Usambaras or at Dakatcha, but in both areas this species inhabits some form of lowland forest (Evans 1997). Furthermore, in logged parts of the Usambaras, Sokoke Scops Owl densities were half that of unlogged forests, emphasising the dependence of this species on undisturbed lowland forest. Not surprisingly, this species has been flagged as being at high risk of extinction in the medium term (Collar et al. 1994). Disturbingly, the population of this species has been documented to be in decline at ASF from an estimated 1,025 pairs in 1993 down to 800 pairs in 2008 (Virani et al. 2010).

In this paper, we investigate the possible effects of climate change on the distribution of the Sokoke Scops Owl. Our primary aim is to assess the likelihood of long-term persistence of this species. Our approach is to use niche modelling to describe the current distribution of the species, and then project its distribution into the future. Our specific objectives are: 1) to model the current distribution of the Sokoke Scops Owl using Maxent (Phillips et al. 2006), and 2) to model its distribution in 2080 under the IPCC Special Report on Emission Scenarios (SRES) scenario A2. The rationale for our approach is that modelling will allow us to predict the future distribution of this endangered species and therefore develop a conservation management plan for this species in light of the ongoing change in global climate.

\section{Methods}

\section{Study sites}

The known global distribution of the Sokoke Scops Owl ranges patchily from approximately $3^{\circ}$ to $5^{\circ} \mathrm{S}$ and from $38^{\circ}$ to $40^{\circ} \mathrm{E}$, making it a narrow-ranged East African endemic. Hence, we designated our study area from $1.5^{\circ}$ to $7.5^{\circ} \mathrm{S}$ and from $38^{\circ}$ to $42^{\circ} \mathrm{E}$ (Figure 1). Much of the natural habitat of the Sokoke Scops Owl (i.e. coastal lowland forest) within this region has been transformed, degraded or disturbed (Thompson et al. 2007), the existing tracts being fragmented and isolated (Figure 1).

\section{Data collection}

The distribution of the Sokoke Scops Owl was based on published (Evans 1997, Virani et al. 2010) and unpublished (C. Jackson unpubl. data) sources, totalling 42 point locations (Figure I). Additionally, surveys were conducted in apparently suitable habitat in southern coastal Kenya 


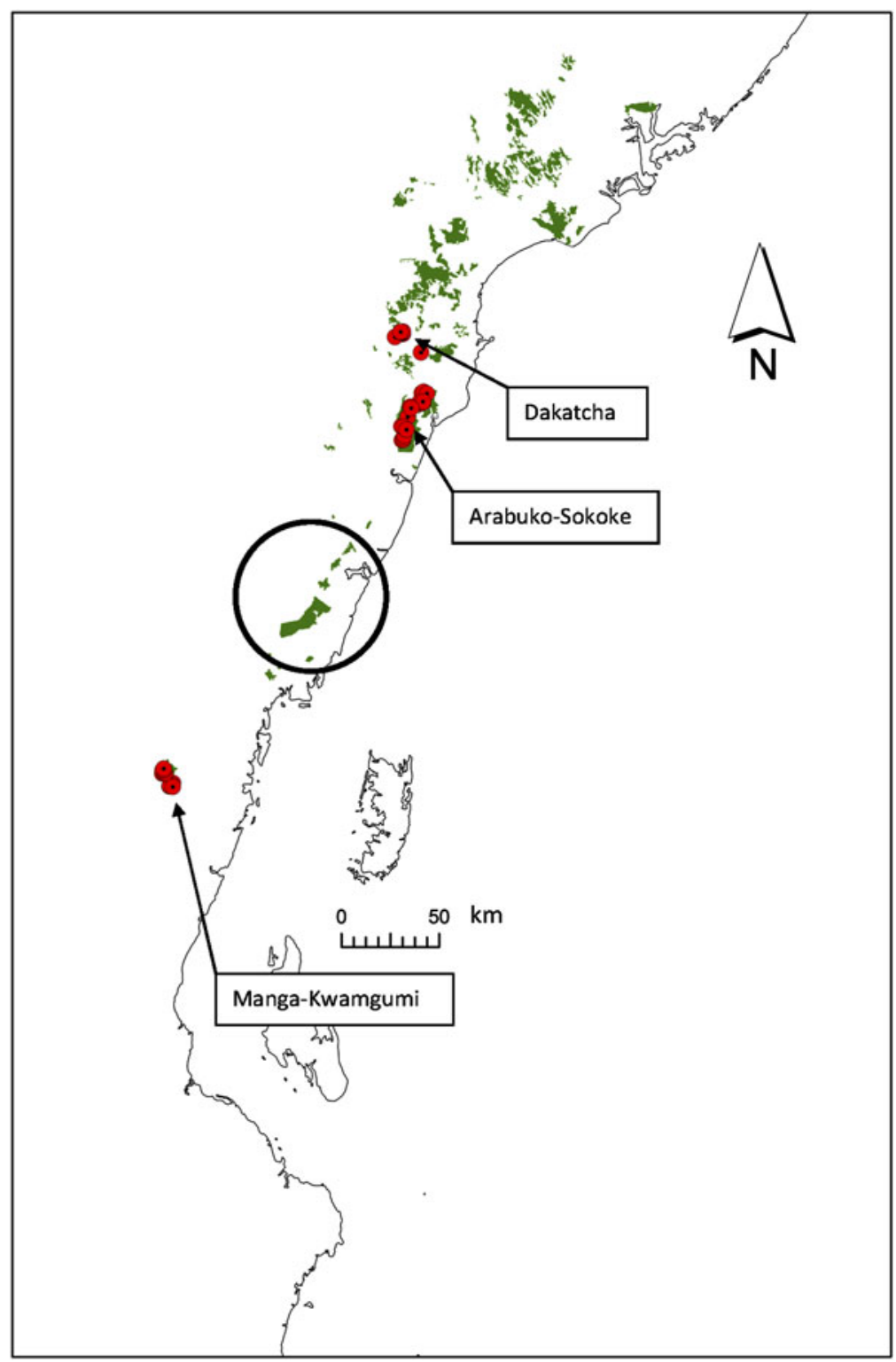

Figure 1. The distributions of: Sokoke Scops Owl (red circles); lowland coastal forest (green); the three forests with known populations of Sokoke Scops Owl (arrows); and the location of the Kaya forests (enclosed by the circle), in Kenya and northern Tanzania.

(between Mombasa and the Tanzanian border) where this species has not been recorded before, but where suitable climatic conditions are predicted to occur (see Results below). A total of nine Kaya forests (comprising pristine coastal forest habitat) were surveyed for the presence of Sokoke Scops Owl. These nine forests, in order of increasing size, are: Kaya Waa (20 ha), Diani (8o ha), Gandini (150 ha), Mtswakara (247 ha), Mrima Hill (250 ha), Dzombo Hill (295 ha), Mwache (345 ha), Marenje Hill (1,480 ha), and Shimba Hills (9,500 ha) lying 30-300 m above sea level. 
Each of the Kaya forests was visited once in either August-September 2007 or August 2008. Each forest was surveyed over two nights, with an early evening 19hoo-22hoo and an early morning session 03hoo-06hoo. Survey methods followed Virani et al. (2010) and involved 10-min owl counts at points separated by $200 \mathrm{~m}$. At the beginning of each point, owl calls were elicited for 30 seconds using pre-recorded Sokoke Scops Owl calls recorded from ASF.

\section{Niche modelling}

Niche modelling involves predicting the geographical distribution of a species based on environmental conditions at locations where the species is known to occur (presence only data), and has become a popular and effective tool in conservation biology, ecology, evolution and phylogeography (Townsend and Robins 2003, Graham et al. 2004, Martinez-Meyer et al. 2004, Ficetola et al. 2007, Raxworthy et al. 2007, Lamb et al. 2008). A number of different modelling techniques have been developed for such "presence only" datasets, of which Maxent (maximum entropy; Phillips et al. 2006) has consistently performed well (Elith et al. 2006, Phillips and Dudik 2008, Wisz et al. 2008). Furthermore, it has been suggested that Maxent performs well even when dealing with a small number of occurrence records (Hernandez et al. 2006, Pearson et al. 2007, Wisz et al. 2008).

One categorical and eight continuous environmental variables were used as predictors in the Maxent models; these variables are listed in Table 1 . The continuous variables included a digital elevation model (SRTM3O) or were extracted from WorldClim (Hijmans et al. 2005; www. worldclim.org). The only categorical variable included was a soil map extracted from the harmonised world soil database (FAO/IIASA/ISRIC/ISSCAS/JRC 2009). All the environmental variables were resampled to a grid resolution of $30 \operatorname{arcsec}$ (roughly 1 x I km) and clipped to eastern Kenya and north-eastern Tanzania using ArcView 3.2 and the extension Garp Datasets. All models were run with the seven BioClim variables, the elevation model and the soil map. The 42 presence records correspond to 35 pixels ( 1 x 1 km).

The Maxent model was run with $75 \%$ training and $25 \%$ random test data, and the regularisation multiplier was set to $I$ (Lamb et al. 2008). All other Maxent settings were left on default. Model performance was evaluated by examining the area under the receiver operating characteristic curve (AUC), and by a jack-knife test which examines the importance of each environmental variable, first by removing one variable at a time and then each variable in isolation (Phillips et al. 2006).

Maxent provides an output of the relative suitability for a species as a continuous variable. We converted this into a binary variable by applying a threshold, produced by Maxent. Hence, values below the threshold indicate areas that were unsuitable for the species, whereas values above the threshold were those that were suitable. The logistic threshold "Equal Training Sensitivity and

Table 1 . The one categorical and eight continuous environmental variables used in the Maxent modelling of the predicted global distribution of the Sokoke Scops Owl.

\begin{tabular}{lll}
\hline Name & Description & Type \\
\hline Altitude & SRTM30 digital elevation model & Continuous \\
Bio 02 & Mean diurnal range & Continuous \\
Bio 03 & Isothermality & Continuous \\
Bio 07 & Annual temperature range & Continuous \\
Bio 09 & Mean temperature of driest month & Continuous \\
Bio 12 & Annual precipitation & Continuous \\
Bio 15 & Precipitation seasonality & Continuous \\
Bio 19 & Precipitation of coldest month & Continuous \\
Soil & Harmonised World Soil Dataset & Categorical \\
\hline
\end{tabular}


Specificity" gave the most realistic current distribution prediction for the Sokoke Scops Owl and we therefore used it for all the models.

We projected the future distribution of the Sokoke Scops Owl by using the $\mathrm{HadCM}_{3}$ general circulation model (Gordon et al. 2000). We extracted the same bioclimatic data as was used above to model the predicted current distribution from the WorldClim site (www.worldclim.org) for 2080 under the "A2" scenario. This scenario depicts a heterogeneous future world based on a high human population growth rate coupled with increased energy expenditure and large land-use changes (i.e. higher $\mathrm{CO}_{2}$ emissions). We used the "clamp" feature in Maxent to this future prediction which restricts the effect of projecting onto environmental features not present in the training dataset (Pyron et al. 2008). The protected areas were extracted from the 2012 World Database on Protected Areas (WDPA), which is a joint project of UNEP and IUCN (www.wdpa.org).

\section{Results}

The potential current distribution of the Sokoke Scops Owl is shown in Figure 2a. This model has a good fit (training AUC $=0.996$, test $\mathrm{AUC}=0.990$ ), but produces a potential distribution that is only partially realised. Some areas (e.g. to the south of ASF) showing as highly suitable have in fact been transformed and the native forest has been replaced with an agricultural landscape unsuitable for Sokoke Scops Owl. The jack-knife test for the model indicated that soil type and precipitation of the coldest quarter (Bio 19), both with regularised training gains of $>_{1}$.0, were the most important variables; they contributed $57.3 \%$ and $30.3 \%$ of the explanatory power of the model, respectively. The response curves showing the way the seven bioclimatic variables affect the predicted distributions are presented in Figure 3. The variables isothermality (the mean diurnal range divided by the temperature annual range; Bio 03) and precipitation seasonality
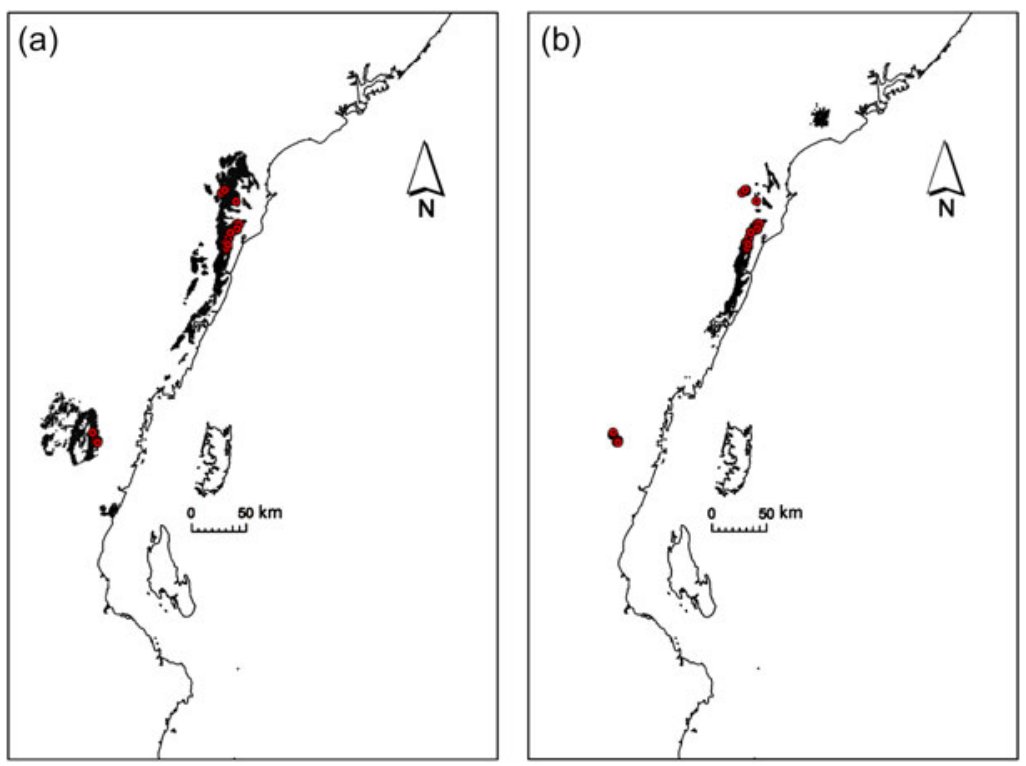

Figure 2. The modelled current (a), and future (b) distribution of Sokoke Scops Owl based on Maxent using the seven bioclimatic variables, altitude and soil (see text for further details of the variables). The future distribution is based on $\mathrm{HadCM}_{3}$ model "A2" which represents an economically-orientated world with high human population growth rate, increased energy expenditure and accelerated land-use changes. 

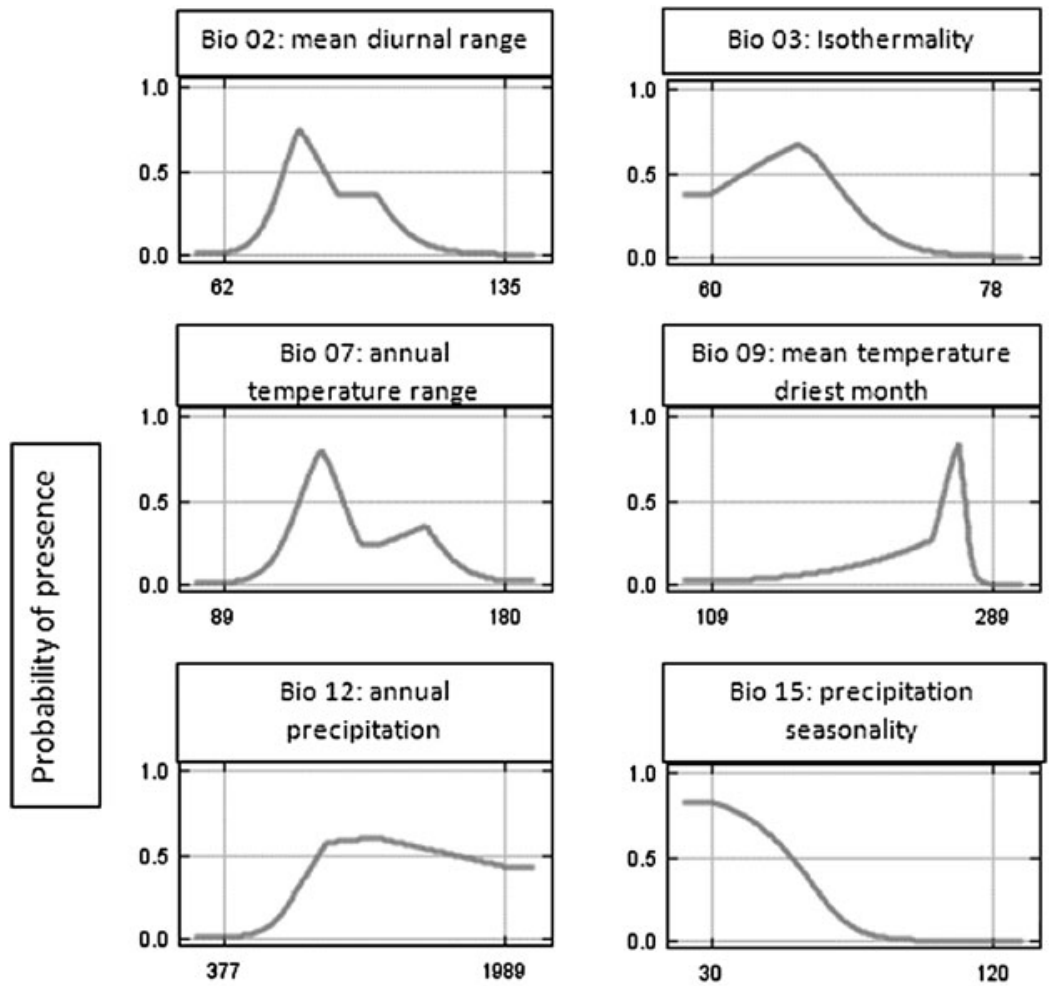

108
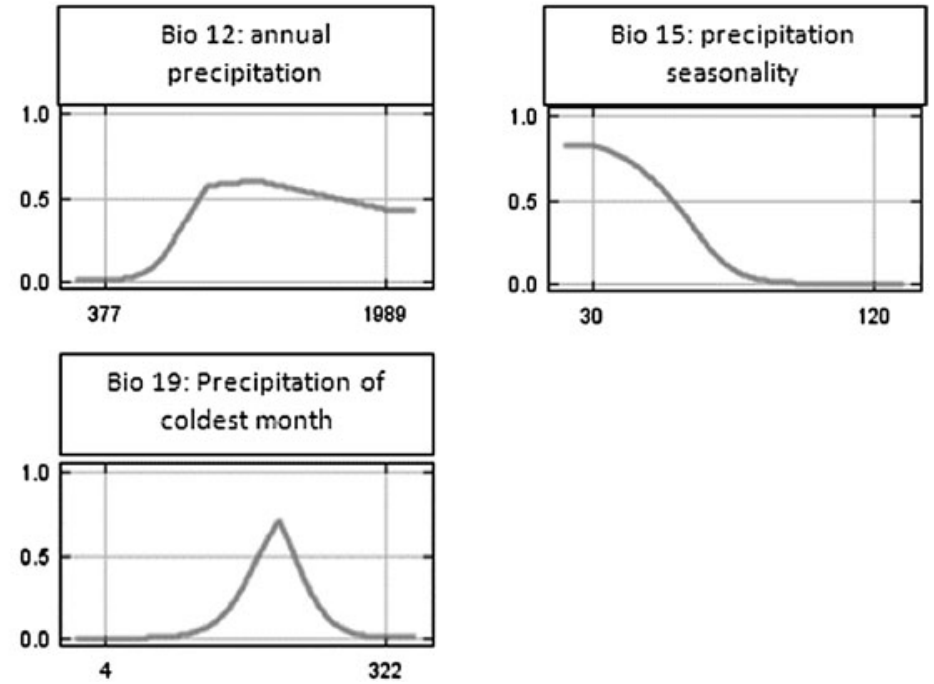

Figure 3. Response curves showing how each of the seven bioclimatic variables affects the Maxent model presented in Figure 2. The seven bioclimatic variables are described in Table 1 . The $\mathrm{X}$-axes are the variables (note that temperature values are all in degrees Celsius $\mathrm{x}$ 10, e.g. mean temperature of the driest month is scaled from 10.9 to 28.9 degrees Celsius). The Y-axes are the probability of presence for the species in relation to the variable, if there were no other variables used in the model. This is the preferred metric to look at the influence of each variable where there is autocorrelation across variables.

(Bio 15) are inversely related while mean temperature of the driest month (Bio o9) and annual rainfall (Bio 12) are directly related. In contrast, the other variables tended to increase to a peak and then decline again. The bioclimatic suitability model for the Sokoke Scops Owl, therefore, emphasises high, year-round rainfall with low seasonality.

The surveys of Sokoke Scops Owl in the Kaya forests of southern Kenya failed to record this species in any of the nine forests that were surveyed.

The predicted distribution of the Sokoke Scops Owl in 2080 is shown in Figure $2 b$. The areas with the highest suitability are shifted southwards and eastwards, away from the current core 
distribution of the species in Kenya. In the case of Tanzania, the future predicted distribution does not include any suitable climatic conditions for the Sokoke Scops Owl. Concomitant with a dramatic shift, the actual area of suitable climatic conditions is also predicted to shrink by $64 \%$ in the case of the pixels with highly suitable conditions (Table 2). A more relevant measure to the future conservation of the Sokoke Scops Owl is the predicted number of pixels with highly suitable conditions that fall within protected areas. The current model indicates 840 pixels $\left(\mathrm{c} .840 \mathrm{~km}^{2}\right)$ falling within protected areas, whereas by 2080 this declines to 298 pixels $\left(298 \mathrm{~km}^{2}\right)$, a decline of $65 \%$. It is important to note that the Kwamgumi forest reserve area (and all surrounding suitable areas in the East Usambaras) is lost under the future model.

\section{Discussion}

Our model predicts that the distribution of Sokoke Scops Owl will shift southward and eastward by 2080 . In addition to the shift in the predicted distribution, there are also changes in the amount and location of the suitable environmental space within the distribution. Areas predicted to have high probability-of-presence for the species, or high environmental suitability, decrease by 2080 . Given the already restricted range of the Sokoke Scops Owl, decreases in the amount of area with high environmental suitability is likely to severely increase the extinction risk of the species. Southward and eastward shifts of the whole distribution, or areas of high environmental suitability, may have dire consequences for its long-term persistence. To the south and east of the ASF population of Sokoke Scops Owl are vast areas of highly degraded or entirely transformed landscapes without any suitable habitat for the owls (Thompson et al. 2007). Even more dramatic is the predicted total loss of suitable conditions in the East Usambara population. How this predicted change in future climate will affect the forests currently persisting at these two sites is unknown. However, due to the extremely restricted distribution of the Sokoke Scops Owl, any reduction in suitable habitat is of high conservation concern. Species with high habitat specificity and narrow ranges have been highlighted as the most vulnerable to climate change (Manne and Pimm 2001, Thomas et al. 2004, Williams et al. 2003). Restricted-range species are more vulnerable to extinction overall, due to stochastic events (McKinney 1997), as recognised by the IUCN Red List criteria (IUCN 2001).

Small distributions are often linked to lower abundance and higher habitat specificity (Brown 1984). While we have not directly measured abundance in this study, some predicted patterns may be inferred. The environmental suitability predicted by Maxent has been shown to correlate with species' abundance: where environmental suitability is low, species abundance is generally also low; where environmental suitability is high, species' abundance can range from high to low (VanDerWal et al. 2009). The decrease in suitability within a species's distribution may indicate that the species is likely to decrease in abundance by 2080 .

Many studies have shown that the synergy between climate change and other forms of habitat degradation is driving species towards extinction faster than either factor operating alone (Millenium Ecosystem Assessment 2005). This has been shown for birds in particular at a global scale (Jetz et al. 2007). For the Sokoke Scops Owl, forest destruction in combination with shifting

Table 2. The current and predicted areas of suitable climatic conditions (modelled in Maxent based on seven bioclimatic variables) for the Sokoke Scops Owl under the SRES scenario A2. The values show the number of pixels (3o arc sec) represented within the "Equal Training Sensitivity and Specificity" logistic threshold. This has been done for the entire study area and then separately within existing protected areas. See text for further details of the modelling procedures.

\begin{tabular}{llll}
\hline Number of pixels in entire study area & Number of pixels within protected areas \\
\hline Current & $\mathrm{A}_{2}$ & Current & A2 \\
3564 & 1296 & 840 & 298 \\
\hline
\end{tabular}


climate space may lead to highly limited suitable habitat. In addition, it is shown that current conservation efforts will decrease in efficacy with climate change. Current protected areas may decrease in species richness, as species distributions change with changing climate (Coetzee et al. 2009, Hole et al. 2009). Very little of the future distribution of the Sokoke Scops Owl will overlap with current protected areas. This is the most likely future situation, as current global greenhouse gas emissions are already exceeding the most severe of the IPCC future scenarios (Raupach et al. 2007), making the A2 scenario used in this study very likely.

The future of the Sokoke Scops Owl looks bleak. With predicted decrease in Sokoke Scops Owl distribution, potential decrease in abundance (corresponding to the predicted decrease in suitability), and the lack of suitable protected areas, this owl is facing a very real possibility of extinction within the next 100 years. In addition, the $65 \%$ decline in suitable habitat falling within protected areas and ongoing habitat degradation further emphasises the potential for significant population declines in this species. Given this scenario, and the fact that a $25 \%$ decline in population over the past two decades has already been documented (Virani et al. 2010), we strongly recommend that owl surveys to estimate population size continue at least every two years following the protocol outlined by Virani et al. (2010).

Some conservation interventions may be possible for the Sokoke Scops Owl. Our study has identified the potential suitable climatic space available to this species in the future. It is theoretically possible that reforestation or habitat restoration could create suitable areas for its future distribution (Shoo et al. 2011). Re-evaluation of protected areas, and ideally creating new protected areas, is likely to be crucial to the persistence of many species. In addition to the Sokoke Scops Owl, other threatened or localised species that are likely to benefit from habitat restoration and the proclamation of future protected areas in this region include the following birds: Sokoke Pipit Anthus sokokensis, Clarke's Weaver Ploceus golandi, and Amani Sunbird Hedydipna pallidigaster; and mammals: Sokoke bushy-tailed mongoose Bdeogale omnivora, Aders Duiker Cephalophus adersi and the easternmost race of the African golden cat Felis aurata (Virani 1993).

We suggest that exploratory surveys north of the ASF and the Dakatcha Woodlands, coupled with habitat assessments to identify suitable habitat for the Sokoke Scops Owl should be a priority goal. In addition, a species action plan for the Sokoke Scops Owl urgently needs to be drafted with the possibility of considering translocation of the species as a way of expanding its range (Hoegh-Guldberg et al. 2008). The Kaya forests are the obvious candidate for any such translocation since they fall within the predicted future climatic conditions suitable for this species. The absence of the Sokoke Scops Owl from these Kaya forests is surprising since they form a natural link between the forests in the East Usambaras and the ASF. The possibility of this species having recently gone extinct in these Kaya forests needs to be investigated before any translocations are conducted.

Although the use of niche modelling (in particular Maxent) in conservation has increased steadily in the past few years (Ficetola et al. 2007, Recio and Virgos 2010, Jimenez-Valverde et al. 2010), its effectiveness as a tool for predicting future distributions and status of species has been challenged (Jimenez-Valverde et al. 2008). There are a number of reasons for this including: possible lack of relationship between probability of distribution and abundance (Jimenez-Valverde et al. 2009); confusion of potential and realised distributions (Jimenez et al. 2008); inappropriate use of AUC (Lobo et al. 2007); biases due to small sample size (Wisz et al. 2008); lack of distinction between absence and pseudo-absence data; and obviously the reliance on future climate models that cannot be tested in the present. Hence, the interpretation of our data needs to be carefully considered in light of these observations.

\section{Conclusion}

The combination of the current restricted range of the Sokoke Scops Owl, and the future projections of range shifts and loss into the future, suggest that this species has a high risk of extinction. Niche modelling has provided a useful mechanism in which to predict these likely 
changes in distribution. We strongly recommend close monitoring of this species and suggest the investigation of potential intervention in the form of translocations to other suitable habitat patches currently not known to support populations of the Sokoke Scops Owl.

\section{Acknowledgements}

Financial support for this study was provided by The Peregrine Fund through its Africa programme. We thank the Kenya Wildlife Service and the National Museums of Kenya for their support. We are indebted to David Ngala, Gabriel Katana, Simon Musila, Bernard Cheruiyot Soi and Shiv Kapila for assistance in the field.

\section{References}

Brown, J. H. (1984) On the relationship between abundance and distribution of species. Am. Nat. 124: 255-279.

Coetzee, B. W. T., Robertson, M. P., Erasmus, B. F. N., van Rensburg, B. J. and Thuiller, W. (2009) Ensemble models predict Important Bird Areas in southern Africa will become less effective for conserving endemic birds under climate change. Global Ecol. Biogeogr. DOI: 10.1111/j.14668238.2009.00485.x.

Collar, N. J., Crosby, M. J. and Stattersfield, J. (1994) Birds to watch 2. The world list of threatened birds. Cambridge, UK: BirdLife International.

Elith, J., Graham, C. H., Anderson, R. P., et al. (2006) Novel methods improve prediction of species' distributions from occurrence data. Ecography 29: 129-151.

Erasmus, B. F. N., Van Jaarsveld, A., Chown, S. L., Kshatriya, M. and Wessels, K. J. (2002) Vulnerability of South Africa animal taxa to climate change. Global Change Biol. 8: 679-693.

Evans, T. D. (1997) Preliminary density estimates of the population density of the Sokoke Scops Owl Otus ireneae in the East Usambara lowlands, Tanzania. Afr. J. Ecol. 35: 303-311.

Evans, T. D., Watson, L. G., Hipkiss, A. J., Kiure, J., Timmins, R. J. and Perkin, A. W. (1994) New records of Sokoke Scops Owl Otus ireneae, Usambara Eagle Owl Bubo vosseleri and East Coast Akalat Sheppardia gunningi from Tanzania. Scopus 18: 40-47.

Ficetola, G. F., Thuiller, W. and Miaud, C. (2007) Prediction and validation of the potential global distribution of a problem- atic alien invasive species - the American bullfrog. Diversity Distrib. 13: 476-485.

FAO/IIASA/ISRIC/ISSCAS/JRC (2009) Harmonized World Soil Database (version 1.1). Rome, Italy and Laxenburg, Austria: FAO, IIASA.

Gordon, C., Cooper, C., Senior, C. A., Banks, H., Gregory, J. M., Johns, T. C., Mitchell, J. F. B. and Wood, R. A. (2000) The simulation of SST, sea ice extents and ocean heat transports in a version of the Hadley Centre coupled model without flux adjustments. Climate Dynamics 16: 147-168.

Graham, C. H., Ron, S. R., Santos, J. C., Schneider, C. J. and Moritz, C. (2004) Integrating phylogenetics and environmental niche models to explore speciation mechanisms in dendrobatid frogs. Evolution 58 : 1781-1793.

Hannah, L., Midgley, G. and Millar, D. (2002) Climate change-integrated conservation strategies. Global Ecol. Biogeog. 11: 485-495.

Hernandez, P. A., Graham, C. H., Master, L. L. and Albert, D. L. (2006) The effect of sample size and species characteristics on performance of different species distribution modeling methods. Ecography 29: $773-785$.

Hijmans, R. J., Cameron, S. E., Parra, J. L., Jones, P. G. and Jarvis, A. (2005) Very high resolution interpolated climate surfaces for global land areas. Int. J. Climat. 25:1965-1978.

Hoegh-Guldberg, O., Hughes, L., McIntyre, S., Lindenmayer, D. B., Parmesan, C., Possingham, H. P. and Thomas, D. C. (2008) Assisted colonization and rapid climate change. Science 321: 345-346. 
Hole, D. G., Willis, S. G., Pain, D. J., Fishpool, L. D., Butchart, S. H. M., Collingham, Y. C. Rahbek, C. and Huntley, B. (2009) Projected impacts of climate change on a continent-wide protected area network. Ecol. Lett. 12: 420-431.

Holt, R. D. (2009) Bringing the Hutchinsonian niche into the 21st century: Ecological and evolutionary perspectives. Proc. Natl. Ac. Sci. 106: 19659-19665.

Huntley, B., Collingham, Y. C., Green, R. E., Hilton, G. M., Rahbek, C. and Willis, S. G. (2006) Potential impacts of climatic change upon geographical distributions of birds. Ibis 148: 8-28.

Huntley, B., Collingham, Y. C., Willis, S. G. and Green, R. E. (2008) Potential impacts of climatic change on European breeding birds. PLoS ONE 3(1): e1439. doi:10.1371/ journal.pone.0001439

Huntley, B., Green, R. E., Collingham, Y. C. and Willis, S. G. (2007) A climatic atlas of European breeding birds. Durham, Sandy and Barcelona: Durham University, RSPB and Lynx Edicions.

IPCC (2001) Climate change 2001: Synthesis report. Cambridge: Cambridge University Press.

IUCN (2001) Red List categories and criteria. Version 3.1. Gland, Switzerland: Species Survival Commission.

IUCN (2012) IUCN Red List of Threatened Species. Version 2012.1. www.iucnredlist.org. Downloaded on I April 2012.

Jetz, W., Wilcove, D. S. and Dobson, A. P. (2007) Projected impacts of climate and land-use change on the global diversity of birds. PLoS Biol 5(6): e157. doi:10.1371/ journal.pbio.0050157

Jimenez-Valverde, A., Diniz, F., de Azevedo, E. B. and Borges, P. A. V. (2009) Species distribution models do not account for abundance: the case of arthropods on Terceira Island. Ann. Zool. Fennici 46: 451-464.

Jimenez-Valverde, A., Lira-Noriega, A., Peterson, A. T. and Soberon, J. (2010) Marshalling existing biodiversity data to evaluate biodiversity status and trends in planning exercises. Ecol. Res. 25: 947-957. Jimenez-Valverde, A., Lobo, J. M. and Hortal, J. (2008) Not as good as they seem: the importance of concepts in species distribution modelling. Divers. Distrib. 14: 885-890.
Keith, D. A., Akcakaya, H. R., Thuiller, W., Midgley, G. F., Pearson, R. G., Phillips, S. J., Regan, H. M., Araujo, M. B. and Rebelo, T. G. (2008) Predicting extinction risks under climate change: coupling stochastic population models with dynamic bioclimatic habitat models. Biol. Lett. 4: 560-563.

Kelsey, M. G. and Langdon, T. E. S. (1984) The conservation of Arabuko-Sokoke Forest. Cambridge: International Council for Bird Preservation. (ICBP Study Report No. 4).

Lamb, J. M., Ralph, T. M. C., Goodman, S. M., Bogdanowicz, W., Fahr, J., Gajewska, M., Bates, P. J. J., Eger, J., Benda, P. and Taylor, P. J. (2008) Phylogeography and predicted distribution of African-Arabian and Malagasy populations of giant mastiff bats, Otomops spp. (Chiroptera: Molossidae). Acta Chiropterol. 10: 21-40.

Lobo, J. M., Jimenez-Valverde, A. and Real, R. (2007) AUC: a misleading measure of performance of predictive distribution models. Global Ecol. Biogeogr. DOI: 10.1111/j.14668238.2007.00358.x

Manne, L. L. and Pimm, S. L. (2001) Beyond eight forms of rarity: which species are threatened and which will be next? Anim. Conserv. 4: 221-229.

Martinez-Meyer, E., Peterson, A. T. and Hargrove, W. W. (2004) Ecological niches as stable distributional constraints on mammal species, with implications for Pleistocene extinctions and climate change projections for biodiversity. Global Ecol. Biogeogr. 13: 305-314.

McKinney, M. L. (1997) Extinction vulnerability and selectivity: combining ecological and paleontological views. Ann. Rev. Ecol. Syst. 28: 495-516.

Millennium Ecosystem Assessment (2005) Ecosystems and human well-being: synthesis. Washington, DC and Covelo, CA: Island Press.

Parmesan, C. (2006) Ecological and evolutionary responses to recent climate change. Ann. Rev. Ecol. Evol. Syst. 37: 637-669.

Pearson, R. G., Raxworthy, C. J., Nakamura, M. and Peterson, A. T. (2007) Predicting species' distributions from small numbers of occurrence records: A test case using cryptic geckos in Madagascar. J. Biogeogr. 34: 102-117. 
Phillips, S. J. and Dudik, M. (2008) Modeling of species distributions with Maxent: new extensions and a comprehensive evaluation. Ecography 31: 161-175.

Phillips, S. J., Anderson, R. P. A. and Chapire, R. E. S. (2006) Maximum entropy modeling of species geographic distributions. Ecol. Model. 190: 231-259.

Pounds, J. A., Fogden, M. P. L. and Campbell, J. H. (1999) Biological response to climate change on a tropical mountain. Nature 398: 611-615.

Pyron, R. A., Burbrink, F. T. and Guiher, T. J. (2008) Claims of potential expansion throughout the U.S. by invasive python species are contradicted by ecological niche models. PLoS ONE 3(8): e2931. doi:10.1371/journal.pone.0002931

Raupach, M. R., Marland, G., Ciais, P., Le Quéré, C., Canadell, J. G., Klepper, G. and Field, C. B. (2007). Global and regional drivers of accelerating $\mathrm{CO}_{2}$ emissions. PNAS 104: 10288-10293.

Raxworthy, C. J., Ingram, C. M., Rabibisoa, N. and Pearson, R. G. (2007) Applications of ecological niche modeling for species delimitation: A review and empirical evaluation using day geckos (Phelsuma) from Madagascar. Syst. Biol. 56: 907-923.

Recio, M. R. and Virgos, E. (2010) Predictive niche modelling to identify potential areas of conflicts between human activities and expanding predator populations: a case study of game management and the grey mongoose, Herpestes ichneumon, in Spain. Wildl. Res. 37: 343-354.

Ripley, S. D. (1966) A notable owlet from Kenya. Ibis 108: 136-137.

Shoo, L. P., Storlie, C., VanDerWal, J., Little, J. and Williams, S. E. (2011) Targeted protection and restoration to conserve tropical biodiversity in a warming world. Global Change Biol. 17: 186-193.

Simmons, R. E., Barnard, P., Dean, W. R. J., Midgley, G. F., Thuiller, W. and Hughes, G. (2004) Climate change and birds: perspectives and prospects from southern Africa. Ostrich 75: 295-308.

Stott, P. A., Tett, S. F. B., Jones, G. S., Allen, M. R., Mitchell, J. F. B. and Jenkins, G. J. (2000) External control of 2oth century temperature by natural and anthropogenic forcings. Science 290: 21332137.

Thomas, C. D., Cameron, A., Green, R. E., Bakkenes, M., Beaumont, L. J., Collingham, Y. C., Erasmus, B. F. N., de Siqeira, M. F., Grainger, A., Hannah, L., Hughes, L., Huntley, B., van Jaarsveld, A. S., Midgley, G. F., Miles, L., Ortega-Huerta, M. A., Peterson, A. T., Phillips, O. L. and Williams, S. E. (2004) Extinction risk from climate change. Nature 427: 145-148.

Thompson, H. S., Eshiamwata, G., Githiru, M., Matiku, P. and Ayiemba, W. (2007) Enhanced sustainability at Arabuko-Sokoke Forest: conservation successes, challenges and lessons learnt. Nairobi: Nature Kenya.

Townsend, A. T. and Robins, C. R. (2003) Using ecological-niche modeling to predict Barred Owl invasions with implications for Spotted Owl conservation. Conserv. Biol. 17: 1161-1165.

VanDerWal, J., Shoo, L. P., Johnson, C. N. and Williams, S. E. (2009) Abundance and environmental niche: environmental suitability estimated from niche models predicts the upper limit of local abundance. Am. Nat. 174: 282-291.

Virani, M. Z. (1993) Golden cat in Arabuko Sokoke? East Afr. Nat. Hist. Bull. 23: 51-52.

Virani, M. (1995) Another Sokoke scops owl caught in the Usambaras. Kenya Birds 3: 75-7.

Virani, M. Z., Njoroge, P. and Gordon, I. (2010) Disconcerting trends in populations of the endangered Sokoke Scops Owl Otus ireneae in the Arabuko-Sokoke Forest, Kenya Ostrich 81: 155-158.

Wichmann, M. C., Jeltsch, F., Dean, W. R. J., Moloney, K. A. and Wissel, C. (2003) Implication of climate change for the persistence of raptors in arid savanna. Oikos 102: 186-202.

Williams, S. E., Bolitho, E. E. and Fox, S. (2003) Climate change in Australian tropical rainforests: an impending environmental catastrophe. Proc. R. Soc. Lond. B 270, 1887-1892.

Wisz, M. S., Hijmans, R. J., Peterson, A. T., Graham, C. H. and Guisan, A. (2008) Effects of sample size on the performance of species distribution models. Diversity Distrib. 14: 763-773. 
ARA MONADJEM*

All Out Africa Research Unit, Department of Biological Sciences, University of Swaziland, Private Bag 4, Kwaluseni, Swaziland.

MUNIR Z. VIRANI

The Peregrine Fund, 5668 West Flying Hawk Lane, Boise Idaho 83709 USA and Ornithology Section, Department of Zoology, National Museums of Kenya, P.O Box 40658-oo1oo Nairobi, Kenya.

\section{COLIN JACKSON}

A Rocha Kenya, PO Box 383, Watamu, Kenya and Ornithology Section, Department of Zoology, National Museums of Kenya, P.O Box 40658-oo1oo Nairobi, Kenya.

\section{APRIL RESIDE}

Centre for Tropical Biodiversity and Climate Change, James Cook University, Townsville, Australia.

${ }^{*}$ Author for correspondence; email: ara@uniswa.sz

Received 21 October 2011; revision accepted 26 April 2012; Published online 6 August 2012 